\title{
Photochemical Vapor Generation for the Sensitive Determination of Mercury in Soil and Sediment Samples by Atomic Fluorescence Spectrometry
}

\author{
Yuyu Zhanga, ${ }^{\mathrm{a}, \mathrm{b}}$, Mo Xu ${ }^{\mathrm{b}}$, Chao $\mathrm{Wei}^{\mathrm{c}}$, Shuyue Zhang ${ }^{\mathrm{a}}$, Hang Gao ${ }^{\mathrm{d}}$, and Rui Liu ${ }^{\mathrm{a}, \mathrm{b}, *}$ \\ ${ }^{a}$ Collaborative Innovation Center for Comprehensive Utilization of Panxi Strategic Mineral Resources, \\ College of Material Chemistry and Chemical Engineering, Chengdu University of Technology, \\ Chengdu, Sichuan 610059, P.R. China \\ ${ }^{b}$ State Key Laboratory of Geohazard Prevention and Geoenvironment Protection, \\ Chengdu University of Technology, Chengdu 610059, P.R. China \\ c National Institute of Metrology, Beijing 100029, P.R. China \\ d Xian Lanfeng Environmental Sci. \& Tech. Co. Ltd., Xian 710061, P.R. China
}

\section{INTRODUCTION}

Mercury $(\mathrm{Hg})$ is one of the most toxic elements and has a significant impact on the ecosystem, on human health and notably acts as a potential carcinogen and neural antagonist. It is introduced to the environment from both natural and anthropogenic sources. The anthropogenic origin is attributed to fuel oil combustion, the mineral industry, etc. The natural release of $\mathrm{Hg}$ is generally related with volcanoes and forest fires (1). Due to its toxic nature, there has been a considerable interest in evaluating its properties and the potential environmental impact. Soil and sediment constitute the greatest reservoir of $\mathrm{Hg}$ in the terrestrial ecosystems and are the main pollution route for the aquatic system and the food chain (2). The Hg content in soils generally ranges from 0.003 to $4.6 \mathrm{mg}$ $\mathrm{kg}^{-1}$, with an average value of $0.5 \mathrm{mg} \mathrm{kg}^{-1}$, and even higher than $10,000 \mathrm{mg} \mathrm{kg}^{-1}$ in some contaminated areas (1).

Many different techniques have been developed for the detection, quantification, and speciation of $\mathrm{Hg}$ with improvement in pretreatment methods, analytical methods, and analytical instruments (3-13). Chemical vapor generation (CVG) introduced by Hatch and Ott in 1968 (14) has achieved significant and widespread application thanks to

*Corresponding autbor.

E-mail: liur.ray@gmail.com

\section{ABSTRACT}

Soil and sediment constitute the greatest reservoir of mercury in terrestrial ecosystems, which is the main pollution route for the aquatic system and the food chain. In this work, a sensitive mercury assay was established for the analysis of soil and sediment samples after photochemical vapor generation. Atomic fluorescence spectrometry, a simple and cost-effective analytical technique, was applied as the detection method. The optimization of the experimental parameters, including carrier argon gas flow, shield argon gas flow, formic acid concentration, and UV lamp number, were investigated in detail.

The results indicated that good linearity was obtained between the concentration of mercury and the atomic fluorescence signal intensity. The limit of detection was $0.011 \mathrm{ng} \mathrm{mL}^{-1}$ (LOD, $3 \sigma$ ) with a linear range of 0.05-5 $\mathrm{ng} \mathrm{mL}^{-1}\left(\mathrm{R}^{2}=0.997\right)$. The relative standard deviation (RSD) for $1 \mathrm{ng} \mathrm{mL}^{-1} \mathrm{Hg}$ was found to be $2.6 \%(n=7)$. Finally, the proposed method was applied to the determination of mercury in various soil and stream sediment certified reference materials. The $t$-test shows that the results obtained by the proposed method are not significantly different from the certified values at the confidence level of $95 \%$. its efficient matrix separation method/ability, high analyte transport efficiency, high selectivity, and high sensitivity in combination with atomic absoprtion spectrometry (15). From the perspective of green chemistry, photo-induced CVG (photo CVG) has been demonstrated to be an ideal alternative to conventional CVG $(16,17)$. Volatile elemental, hydrogenated, carboxylated, and alkylated analytes are generated from non-volatile precursors by ultraviolet (UV) irradiation in the presence of low molecular weight organic compounds (18). The photo CVG technique is simple, sensitive, environmentally friendly, and possesses minimum interference from coexisting inorganic ions. Its analytical applications have been demonstrated in the analysis of Cd (19), $\mathrm{Hg}$ (20-23), conventional hydride-forming elements (As, Bi, Sb, Se, Te, Pb) (24-27), transition metals ( $\mathrm{Cu}, \mathrm{Ni}, \mathrm{Co}, \mathrm{Fe})(28$, 29), and non-metals (I) (30). Q.Y. Liu (31) determined the concentration of mercury and methylmercury in seafood by ion chromatography separation and photo CVG atomic fluorescence spectrometric detection. Gao et al. $(22,23)$ developed the isotope dilution inductively coupled plasma mass spectrometric method for $\mathrm{Hg}$ determination in biological tissues and cosmetic samples $(22,23)$. However, the investigation of sensitive photo CVG-based mercury determination in soil and sediment samples has rarely been reported (32). 


\section{Atomic Apectroscopy \\ 1 Vol. 37(5), Sept./Oct. 2016}

In this work, a simple and sensitive photochemical vapor generation method was developed for the determination of $\mathrm{Hg}$ in various soil and sediment samples. The proposed method was to benefit from the high efficient vapor generation of photo CVG and the high sensitivity of atomic fluorescence spectrometry (AFS). AFS instrumentation also has features of multi-element simultaneous detection, simple instrumentation, low capital/running costs, and easy operation $(33,34)$. The schematic of a photo CVG manifold is shown in Figure 1. After leaching the soil and sediment samples by formic acid, the analyte is pumped into the photo CVG reactor, transformed into volatile mercury vapor, and purged to AFS for detection. The optimization of the photochemical vapor generation parameters, analytical performance, and validation of the method by analysis of the certified reference materials are investigated and discussed in detail.

\section{EXPERIMENTAL}

\section{Instrumentation}

The manifold used for this study is a home-made photo CVG reactor and a commercial atomic fluorescence spectrometer (AFS-2202E, Beijing Haiguang Instrument Co., Beijing, P.R. China). The photo CVG reactor consists of UV lamps (253.7 nm, 15 W, Philips Co., Holland) and a quartz tube $(20 \mathrm{~cm} \times$ $1.8 \mathrm{~mm}$ i.d. $\times 2.8 \mathrm{~mm}$ o.d.). The system is wrapped with aluminum

TABLE I

AFS Instrumental Parameters

\begin{tabular}{lr}
\hline Parameters & \multicolumn{1}{c}{ Values } \\
\hline Instrument & AFS-2202E \\
Lamp current & $80 \mathrm{~mA}$ \\
Voltage of PMT & $-280 \mathrm{~V}$ \\
Atomizer height & $8 \mathrm{~mm}$ \\
Carrier gas flow rate & $500 \mathrm{~mL} \mathrm{~min}$ \\
Shield gas flow rate & $900 \mathrm{~mL} \mathrm{~min}{ }^{-1}$ \\
\hline
\end{tabular}

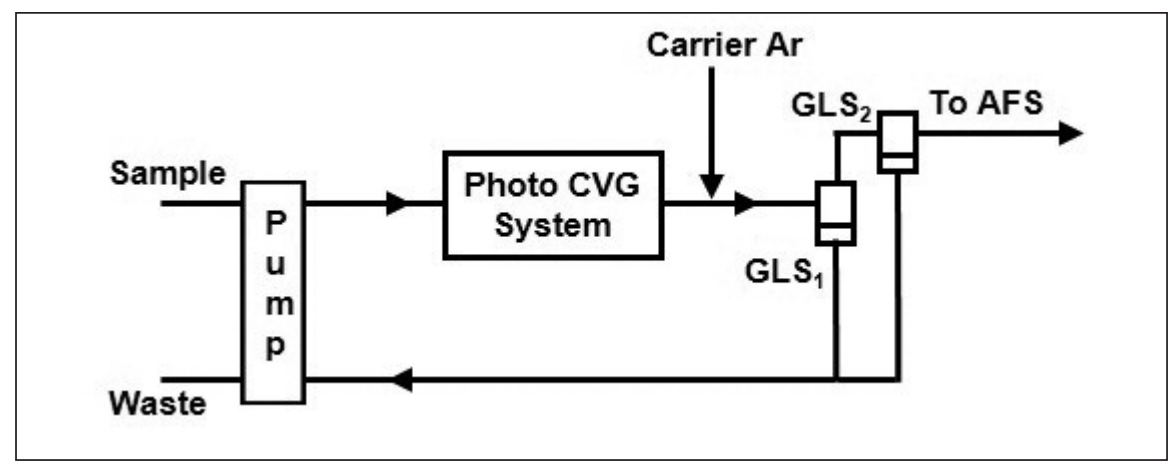

Fig. 1. Schematic of photo CVG manifold.

foil to protect the operator from strong UV radiation and is connected to a tandem set of two gas liquid separators (GLSs) (Chengdu Guoxiang Instrument Co., Ltd., P.R. China). The GLS set can effectively eliminate the water vapor. The instrumental parameters of AFS are summarized in Table I.

\section{Reagents and Samples}

All reagents used in this study were at least of analytical grade. Deionized water (DIW) was used throughout this study. The working solutions were prepared daily by serial dilutions of $1000 \mathrm{mg} \mathrm{L}^{-1} \mathrm{Hg}$ standard stock solution obtained from the National Institute of Metrology (Beijing, P.R. China). All other chemical reagents were purchased from Changzheng Chemical Reagents (Chengdu, P.R. China). The solutions were stored at $4{ }^{\circ} \mathrm{C}$ in the refrigerator. All vessels used in the experiments were soaked overnight in $1 \%(\mathrm{v} / \mathrm{v})$ nitric acid and cleaned sequentially with DIW before use.

Six certified reference materials (CRMs) of GBW 07402 Soil, GBW 07404 Soil, GBW 07447 Soil, GBW 07449 Soil, GBW 07360 Stream Sediment, and GBW 07364 Stream Sediment were used to validate the proposed method for the analysis of soil and sediment samples. The formic acid solubilization procedure was used for the sample treatment of the CRMs (23). Samples of approximately $0.2 \mathrm{~g}$ were weighed into 50-mL dark polyethylene centrifuge tubes and $20 \mathrm{~mL}$ of $20 \%$ (v/v) formic acid was added. Then the centrifuge tube was placed into a shaker at room temperature for 24 hours to solubilize the $\mathrm{Hg}$. The samples were centrifuged at 12,000 rpm for 5 minutes to remove any suspended material. Calibration using the standard addition method was employed for the analysis of all soil and sediment samples to compensate for matrix effects.

\section{Procedure}

The solution containing $\mathrm{Hg}$ and formic acid was transported to the photo CVG system by a flow injection pump and irradiated by UV light during the continuous introduction process. The $\mathrm{Hg}$ vapor generated was carried out by an argon flow after photo CVG. Subsequently, a tandem set of two GLSs was employed for separating the $\mathrm{Hg}$ vapor from the water. The $\mathrm{Hg}$ vapor was introduced into the AFS detector for measurement.

\section{RESULTS AND DISCUSSION}

\section{Optimization of Instrumental Parameters for Photo CVG}

The argon carrier gas flow rate and the shield gas flow rate comprised the two basic parameters determining the $\mathrm{Hg}$ vapor transport efficiency to the AFS. 


\section{Effect of Argon Carrier Gas Flow Rate}

The argon carrier gas served as the sampling gas to bring the generated $\mathrm{Hg}$ vapor to the AFS from the photo CVG system. The effect of the Ar carrier gas flow rate was studied in the range of 300 to 700 $\mathrm{mL} \mathrm{min}^{-1}$. As shown in Figure $2 \mathrm{a}$, optimum sensitivity was obtained at a flow rate of $500 \mathrm{~mL} \mathrm{~min}^{-1}$. At a lower argon flow rate, the baseline was unstable and a tailed peak tended to appear, while a higher argon flow rate could lead to an inferior sensitivity due to the dilution effect in the atomizer (35). The optimized argon carrier gas flow rate of $500 \mathrm{~mL} \mathrm{~min}^{-1}$ was selected for this study.

\section{Effect of Argon Shield Gas Flow}

Argon shield gas is used to prevent extraneous air from entering the $\mathrm{Ar} / \mathrm{H}_{2}$ flame and to ensure its stability $(36,37)$. Contamination from oxygen in extraneous air may result in a reaction of the free atoms with oxygen and hence, decrease the free atom population. The effect of the Ar shield gas flow rate was studied ranging from 700 to $1100 \mathrm{~mL} \mathrm{~min}^{-1}$. As shown in Figure $2 \mathrm{~b}$, the optimum shield gas (Ar) flow rate was found to be $900 \mathrm{~mL}$ $\mathrm{min}^{-1}$. A lower flow rate may cause contamination from the oxygen in extraneous air, resulting in a reaction of the free atoms with oxygen and hence, decrease the free atom population. On the contrary, a flow rate higher than $900 \mathrm{~mL} \mathrm{~min}^{-1}$ may cause dilution of the $\mathrm{Hg}$ atoms in the $\mathrm{Ar} / \mathrm{H}_{2}$ flame. Thus a $900 \mathrm{~mL} \mathrm{\textrm {min } ^ { - 1 }}$ argon shield gas flow rate was chosen for all subsequent measurements.

\section{Optimization of UV Irradiation for Photo CVG}

The formic acid concentration and the UV light intensity comprised the two significant parameters determining $\mathrm{Hg}$ vapor generation efficiency.

\section{Effect of Formic Acid Concen- tration}

The effect of the formic acid concentration ranging from 5\% to $40 \%$ on the response of $\mathrm{Hg}$ is shown in Figure 3. The Hg fluorescence intensity enhanced with an increase in formic acid concentra- tion from 5 to $20 \%(\mathrm{v} / \mathrm{v})$, and levelled off as the concentration of the formic acid increased further. At low formic acid concentration, the co-existing compounds in the sample digest may react with and quench the radicals generated by the photo decomposition of the

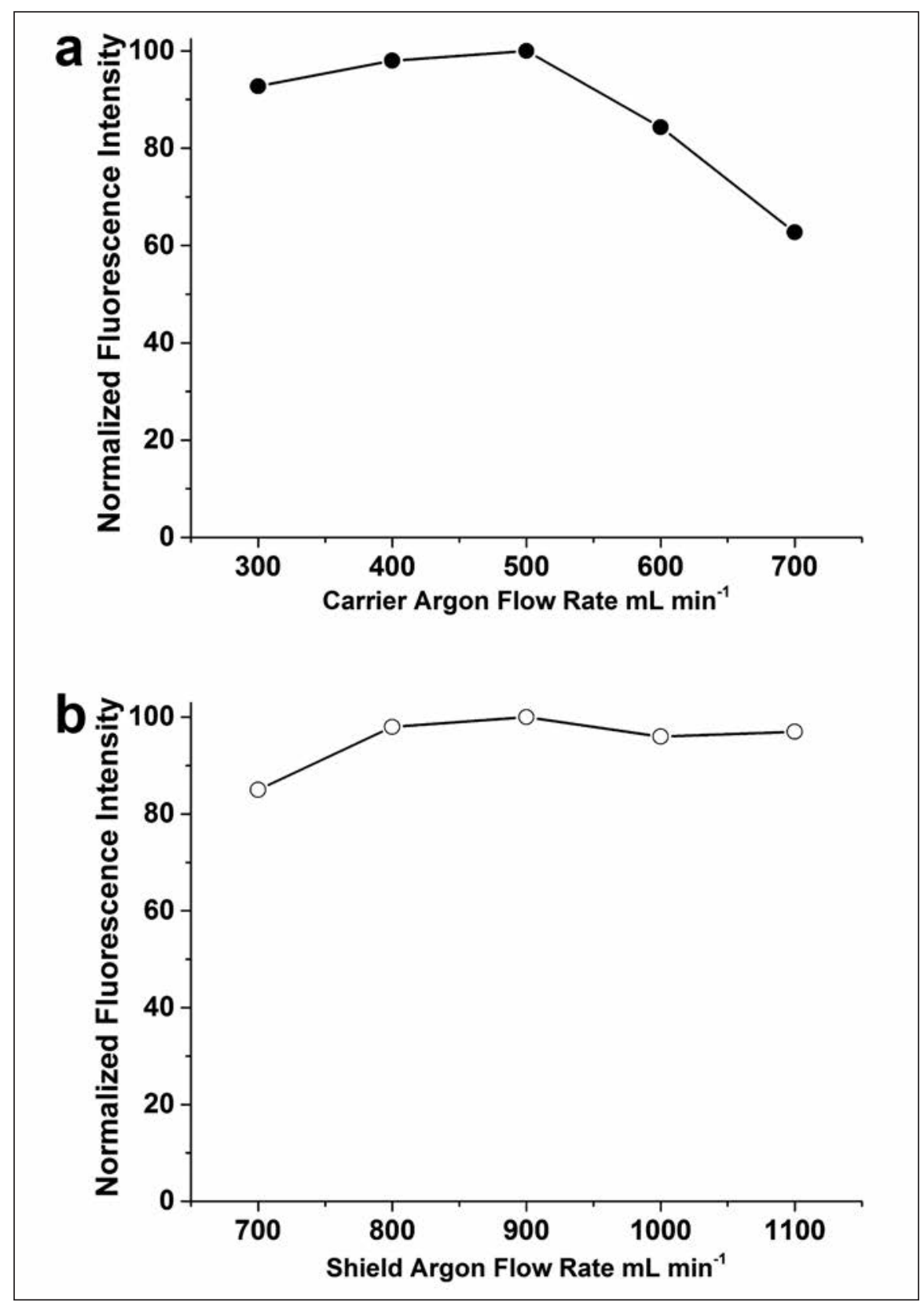

Fig. $2(a \& b)$. The effect of carrier argon flow rate and shield argon flow rate on the fluorescence signal intensity of mercury. 


\section{Atomic Apectroscopy \\ 1 Vol. 37(5), Sept./Oct. 2016}

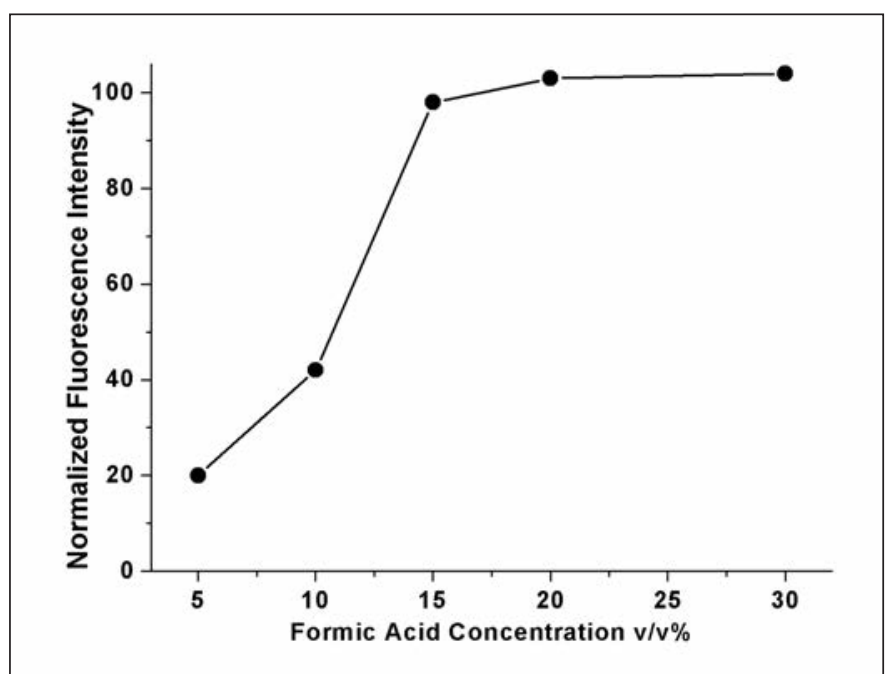

Fig. 3. Effect of formic acid concentration on the fluorescence signal intensity of mercury.

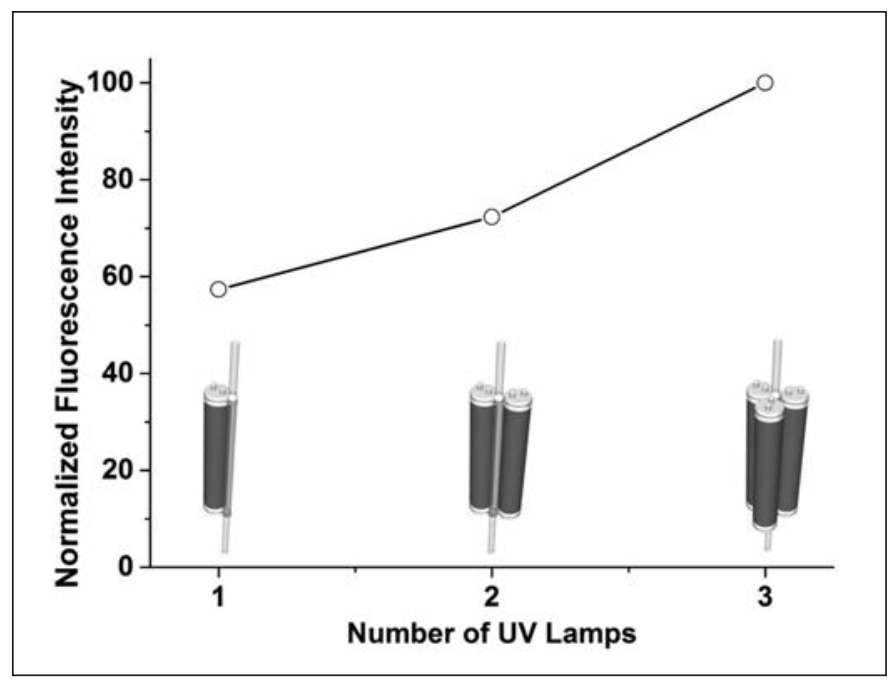

Fig. 4. Effect of number of UV lamps on the fluorescence signal intensity of mercury. formic acid, which consequently reduces the radicals available for $\mathrm{Hg}$ reduction. With an increase in concentration of formic acid, the amount of available radicals increases significantly, resulting in an increase in $\mathrm{Hg}$ reduction efficiency. In consideration of both sensitivity and reagent savings, 20\% of formic acid was chosen for further study.

\section{Effect of UV Lamp}

UV light intensity can remarkably affect the photo CVG efficiency (38). Since low light intensity usually results in insufficient generation of $\mathrm{Hg}$ vapor, use of multiple UV lamps were explored in the photo CVG system to provide abundant UV irradiation. As indicated in Figure 4, the signal intensity increases almost linearly with an increase in the number of UV lamps. Consequently, three UV lamps were employed in the irradiation system for further investigation.

\section{Analytical Performance}

Using optimum conditions, the analytical performance of the present method was evaluated. The

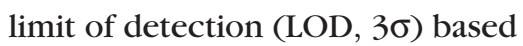

TABLE II

Analytical Results of CRMs in Comparison With Certified Values ( $n=3$ for each sample)

\begin{tabular}{lcc}
\hline Sample & Certified $\left(\mu \mathrm{g} \mathrm{g}^{-1}\right)$ & Found $\left(\mu \mathrm{g} \mathrm{g}^{-1}\right)$ \\
\hline GBW 07402 Soil & $0.015 \pm 0.003$ & $0.014 \pm 0.002$ \\
GBW 07404 Soil & $0.59 \pm 0.05$ & $0.57 \pm 0.03$ \\
GBW 07447 Soil & $0.015 \pm 0.003$ & $0.017 \pm 0.002$ \\
GBW 07449 Soil & $0.008 \pm 0.002$ & $0.007 \pm 0.002$ \\
GBW 07360 Stream & $0.108 \pm 0.011$ & $0.105 \pm 0.005$ \\
Sediment & & \\
GBW 07364 Stream & $0.025 \pm 0.005$ & $0.025 \pm 0.002$ \\
Sediment & & \\
\hline
\end{tabular}

on three times the standard deviation of 11 measurements of a blank solution was found to be $0.011 \mathrm{ng}$ $\mathrm{mL}^{-1}$, which is among the most sensitive techniques for $\mathrm{Hg}$ detection (39). The linear range was between 0.05 to $5 \mathrm{ng} \mathrm{mL}^{-1}\left(\mathrm{R}^{2}=0.997\right)$ and the precision for $1 \mathrm{ng} \mathrm{mL} \mathrm{mg}^{-1} \mathrm{Hg}$ was found to be $2.6 \%(n=7)$.

\section{Determination of $\mathrm{Hg}$ in Soil and Sediment Samples}

Since soil and sediment are the primary depositories of anthropogenic $\mathrm{Hg}$, the analysis of soil and sediment samples is of great importance to prevent and to assess toxicological issues (40). In order to demonstrate the applicability and to validate the accuracy of the proposed method, the analysis of various soil and stream sediment certified reference materials was carried out (GBW 07402 Soil, GBW 07404 Soil, GBW 07447 Soil, GBW 07449 Soil, GBW 07360 Stream Sediment, and GBW 07364 Stream Sediment). As shown in Table II, the analytical results of the proposed method are in good agreement with the certified values. The $t$-test was used to evaluate the significant difference between the certified value and the obtained value of these CRMs, with no significant difference at the $95 \%$ confidence level. 


\section{CONCLUSION}

A photo CVG-AFS method was successfully developed for the determination of trace mercury in soil and stream sediment samples. The proposed method is simple, fast, and cost-effective, sensitive and accurate for the analysis of soils and stream sediments. Minimal chemical reagent consumption (formic acid) was used to make it an environmentally friendly methodology. Due to these attractive features, the proposed method has great potential for the determination of other photochemical vapor generation elements in soils and stream sediments.

\section{ACKNOWLEDGMENTS}

The authors gratefully thank the Opening Fund of the State Key Laboratory of Geohazard Prevention and Geoenvironment Protection (Chengdu University of Technology, No. SKLGP2015K009), the National Natural Science Foundation of China (No. 21505008), and the Scientific Research Fund of the Education Department of Sichuan Province (No. 15ZB0067) for financial support of this project.

Received April 10, 2016.

\section{REFERENCES}

1. T. Frentiu, A.I. Mihaltan, M. Senila, E. Darvasi, M. Ponta, M. Frentiu, and B.P. Pintican, Microchem. J. 110, 545 (2013).

2. C. Gil, J. Ramos-Miras, L. Roca-Perez, and R. Boluda, Chemosphere 78, 409 (2010).

3. E. Stanisz, J. Werner, and H. Matusiewicz, Microchem. J. 114, 229 (2014).

4. J. Xue, S.F. Gong, X.M. Wang, Y.L. Fan, and X. Li, Anal. Lett. 45, 2257 (2012).

5. B. Wang, C.B. Zheng, J.W. Wang, L. Feng, S.B. Li, D.Z. Dan, and G.
Leng, Spectrosc. Spect. Anal. 32, 1106 (2012).

6. R.L. Franklin, J.E. Bevilacqua, and D.I.T. Favaro, Quim. Nova 35, 45 (2012).

7. P. Liang, J. Yu, E.J. Yang, and Y.J. Mo, Food Anal. Methods 8, 236 (2015).

8. C.L. He, G.L. Cheng, C.B. Zheng, L. Wu, Y.I. Lee, and X.D. Hou, Anal. Methods 7, 3015 (2015).

9. R. Gras, J. Luong, and R.A. Shellie, Anal. Chem. 87, 11429 (2015).

10. R. Fernandez-Martinez, I. Rucandio, I. Gomez-Pinilla, F. Borlaf, F. Garcia, and M.T. Larrea, J. Food Compos. Anal. 38, 7 (2015).

11. A.S. Camera, T.A. Maranhao, F.J.S Oliveira, J.S.A. Silva, and V.L.A. Frescura, J. Brazil. Chem. Soc. 26, 2116 (2015).

12. A. de Jesus, R.E. Sturgeon, J.X. Liu, and M.M. Silva, Microchem. J. 117, 100 (2014).

13. C. Ibanez-Palomino, J.F. LopezSanchez, and A. Sahuquillo, Int. J. ENviron. An. Ch. 92, 909 (2012).

14. W.R. Hatch and W.L. Ott, Anal. Chem. 40, 2085 (1968).

15. I. Brindle, Anal. Bioanal. Chem. 388, 735 (2007).

16. P. Wu, L.A. He, C.B. Zheng, X.D. Hou, and R.E. Sturgeon, J. Anal. At. Spectrom. 25, 1217 (2010).

17. Y. Gao, R. Liu, and L. Yang, Chin. Sci. Bull. 58, 1980 (2013).

18. X. Guo, R.E. Sturgeon, Z. Mester, and G.J. Gardner, Anal. Chem. 75, 2092 (2003).

19. J.A. Nobrega, R.E. Sturgeon, P. Grinberg, G.J. Gardner, C.S. Brophy, and E.E. Garcia, J. Anal. At. Spectrom. 26, 2519 (2011).

20. R.E. Sturgeon and V. Luong, J. Anal. At. Spectrom. 28, 1610 (2013).

21. Y. Gao, Z.M. Shi, Z. Long, P. Wu, C.B. Zheng, and X.D. Hou, Microchem. J. 103, 1 (2012).

22. Y. Gao, Z. Shi, Q. Zong, P. Wu, J. $\mathrm{Su}$, and R. Liu, Anal. Chim. Acta 812, 6 (2014)

23. R. Liu, M. Xu, Z. Shi, J. Zhang, Y. Gao, and L. Yang, Talanta 117, 371 (2013).
24. Y. Gao, R.E. Sturgeon, Z. Mester, X.D. Hon, C.B. Zheng, and L. Yang, Anal. Chem. 87, 7996 (2015).

25. Y. Gao, R.E. Sturgeon, Z. Mester, X. Hou, and L. Yang, Anal. Chim. Acta 901, 34 (2015).

26. Y. Gao, M. Xu, R.E. Sturgeon, Z. Mester, Z.M. Shi, R. Galea, P. Saull, and L. Yang, Anal. Chem. 87, 4495 (2015).

27. C. Zheng, Q. Ma, L. Wu, X. Hou, and R.E. Sturgeon, Microchem. J. 95, 32 (2010).

28. C.B. Zheng, L. Yang, R.E. Sturgeon, and X.D. Hou, Anal. Chem. 82, 3899 (2010).

29. Y. Gao, R.E. Sturgeon, Z. Mester, E. Pagliano, R. Galea, P. Saull, X. Hou, and L. Yang, Microchem. J. 124, 344 (2016)

30. P. Grinberg, Z. Mester, A. D'Ulivo, and R.E. Sturgeon, Spectrochim. Acta B 64, 714 (2009).

31. Q.Y. Liu, Microchem. J. 95, 255 (2010).

32. Y.G. Yin, J.F. Liu, and G.B. Jiang, Trac-Trends Anal. Chem. 30, 1672 (2011).

33. Y. Hu, X.R. Hu, H. Liu, L. Huang, and R. Liu, Atom. Spectrosc. 35, 90 (2014).

34. X. Xu, R. Liu, C. Wei, W. Qiu, and Y. Gao, Atom. Spectrosc. 34, 238 (2013).

35. L.W. Liu, H.L. Zheng, C. Yang, L. Xiao, Y.L. Zhangluo, and J.Y. Ma, Spectrosc. Lett. 47, 604 (2014).

36. R. Liu, P. Wu, K.L. Xu, Y. Lv, and X.D. Hou, Spectrochim. Acta B 63 , 704 (2008).

37. R. Liu, P. Wu, M.Y. Xi, K.L. Xu, and Y. Lv, Talanta 78, 885 (2009).

38. Y. Gao, X.H. Peng, Z.M. Shi, R.X. Zhang, X.F. Xia, F.R. Yue, and R. Liu, Atom. Spectrosc. 33, 73 (2012).

39. Y. Gao, Z. Shi, Z. Long, P. Wu, C. Zheng, and $\mathrm{X}$. Hou, Microchem. J. 103, 1 (2012).

40. M. Hlodak, P. Matus, and M. Urik, Chem. Listy 108, 1119 (2014). 